\title{
GUERRA CIVIL Y MILITANCIA EN CATALUÑA: LAS PARTICULARIDADES DEL PERFIL IDEOLÓGICO Y SOCIAL DE LOS MILITANTES DEL PSUC, 1936-1939*
}

\author{
por \\ JOSEP PUIGSECH FARRÀS \\ Universitat Autònoma de Barcelona
}

RESUMEN: El artículo analiza el perfil ideológico y social de los militantes del PSUC durante el conflicto bélico de 1936-1939, contextualizándolo en el marco del movimiento comunista internacional dirigido desde la IC. Se analizan las similitudes y las diferencias de la composición social y, especialmente ideológica, del PSUC, con la de los principales partidos comunistas de Europa Occidental (el PCF, el PCI y el PCE); así como la especificidad que supuso el PSUC dentro de las filas de la IC desde el punto de vista su militancia. Para ello se ban utilizado fuentes primarias inéditas procedentes del antiguo Instituto de Marxismo-Leninismo de la URSS, actualmente Centro Ruso de Conservación y Estudio de la Documentación de la Historia Contemporánea, así como del Archivo Histórico del PCE, prensa de época y memorias de militantes.

Palabras clave: PSUC. IC. Militancia. Composición ideológica y social.

ABSTRACT: This article analyses the social and political profile of PSUC militants during the Spanish Civil War (1936-1939), in the context of the international communist movement. It analyses the similarities and differences in the social and, above all, ideological composition between the PSUC and the main communist parties of Western Europe (PCF, PCI and PCE). Moreover, the article also explores the exceptional nature PSUC's militancy. For this purpose I bave used unedited

* Este artículo se ha elaborado teniendo como punto de referencia mi trabajo de investigación de nueve créditos que fue presentado en la Universitat Autònoma de Barcelona el 30 de septiembre de 1998, bajo la siguiente referencia: PUIGSECH, Josep: El Partit Socialista Unificat de Catalunya i la Internacional Comunista durant la Guerra Civil (1936-1939), Bellaterra, 1998 + 361 págs. El citado trabajo fue elaborado gracias a una beca de investigación del Comissionat per a Universitats i Recerca de la Generalitat de Catalunya.

Hispania, LXII/1, núm. 210 (2002) 259-282 
sources from the former USSR Marxism-Leninism Institute, now called Russian Centre for the Conservation and Study of the Documentation of Modern History, and also the Historical Archives of the PCE, the contemporary press, and memoirs by party members.

KEY WORDS: PSUC. Comintern. Communism. PCE.

El 19 de julio de 1936 estallaba en Barcelona la insurrección militar. Pocos días después, y una vez derrotada la insurrección en la capital catalana, aparecía en escena un nuevo partido político. Así, el 24 de julio de 1936 nacía el PSUC, como resultado de la fusión de dos organizaciones procedentes del ámbito socialista catalán, la USC y FC del PSOE; y de dos organizaciones procedentes del espectro comunista catalán, el PCP y el PCC ${ }^{1}$. El nuevo partido disponía de un reducido número de militantes que no le permitía competir en fuerza y en presencia social con la organización hegemónica en Cataluña en estos momentos, la CNT, al mismo tiempo que ello le condenaba a ocupar un lugar de tercera fila dentro de la política catalana.

Si hacemos caso del informe inédito que el secretario general del PSUC, Joan Comorera, presentó a la dirección de la IC el 20 de febrero de 1938, el PSUC nacía con unos $5.000 / 6.000$ militantes, aunque no especificaba su procedencia, pero reconocía que la USC y el PCC aportaban el mayor número de militantes: «De los cuatro partidos marxistas el principal era la Unió Socialista y el Partit Comunista de Catalunya, pero los cuatro tenían en total entre 5.000 y 6.000 miembros» ${ }^{2}$. Teniendo ésto presente, podemos afirmar que la USC

1 La historiografía había aceptado el 23 de julio de 1936 como fecha de nacimiento del PSUC en base a la afirmación, con escasas pruebas documentales, que en su día realizó la historiadora soviética Ponamariova, L.: La formación del Partit Socialista Unificat de Catalunya, Barcelona 1977, pág. 100.

No obstante, en el informe inédito que el secretario general del PSUC, J. Comorera, presentó a la dirección de la IC el 20 de febrero de 1938, éste afirmaba con rotundidad que «el 24 de julio se producía la fundación del Partit Socialista Unificat de Catalunya». Fuente: CRCEDHC. Fondo 495, circunscripción 74, caso $n^{\circ} 215$. COMORERA, Joan: Informe del camarada Comorera sobre el Partit Socialista Unificat de Catalunya, Moscú 20/02/38, pág. 5. Original en ruso.

Además, y reforzando esta tesis, la $1^{\text {a }}$ Conferencia Nacional del PSUC, que tenía como objetivo hacer un balance de la trayectoria del partido durante su primer año de vida, se celebraba del 24 al 26 de julio de 1937, o sea, comenzaba exactamente 1 año después del 24 de julio de 1936.

2 CRCEDHC. Fondo 495, circunscripción 74, caso $n^{\circ} 215$. COMORERA, Joan: Informe del camarada Comorera..., op. cit., pág. 2. Esta afirmación da la razón a aquellas interpretaciones que consideraban a la baja el número inicial de militantes del PSUC. El primer ejemplo lo proporcionaba la propia autora soviética PONAMARIOVA, L: La formación..., op. cit., pág. 100 , que cifró en 6.000 el número total de militantes iniciales del PSUC (a saber, 2.000 de la USC, 2.000 del PCC, 1.500 de la FC del PSOE, y 500 del PCP). Un segundo ejemplo, con una cifra final ligeramente superior, correspondía a MARTín RAMOS, José Luis: Els orígens del Partit Socialista Unificat de Catalunya (19301936), Barcelona 1977, pág. 233, que la cuantificaba en 6.800 militantes (concretamente, unos

Hispania, LXII/1, núm. 210 (2002) 259-282 
aportaba más del $50 \%$ de esos militantes, es decir, unos 3.000/2.500 militantes; el PCC alrededor de un 30\%, o sea, unos 1.800/1.500; la FC del PSOE un $10 \%$, es decir, unos 300/250; y el PCP un 5\%, o sea, 150/125.

Una primera aproximación al perfil de esos militantes, que se puede llevar a cabo en función de sus características ideológicas, revelaba la originalidad de la nueva formación política catalana: 1) En primer lugar, en el PSUC convergían socialistas y comunistas y, lo que era más importante, lo hacían en pie de igualdad entre sí, ya que ésta era la voluntad del nuevo partido. Ahora bien, entre los primeros debemos diferenciar aquellos que procedían de la USC, que se ubicaban en un grado intermedio entre el socialismo radicalizado y el socialismo reformista (más cercanos al segundo que no al primero), y aquellos que procedían de la FC del PSOE, enmarcados dentro del socialismo radicalizado; mientras que, respecto a los segundos, los antiguos militantes del PCP se definían genéricamente como marxistas, y los procedentes del PCC lo hacían como marxistas-leninistas-estalinistas; 2) y, en segundo lugar, la inmensa mayoría de los militantes del PSUC, además de ser socialistas o comunistas, a su vez eran nacionalistas. Especialmente aquellos que procedían de las dos organizaciones más implicadas e identificadas con la cuestión nacional catalana, la USC y el PCP, a diferencia de la mayoría de los militantes de la FC del PSOE y del PCC, precisamente las filiales respectivas del PSOE y del PCE en Cataluña.

Así, pues, la composición ideológica de los militantes del PSUC era una auténtica novedad en el mapa de las formaciones políticas de Europa y de la propia España. Al fin y al cabo, en un mismo partido, y en pie de igualdad, no sólo convergían socialistas y comunistas, sino que, muchos de ellos a su vez eran nacionalistas catalanes. Esta composición ideológica tan peculiar del nuevo partido respondía al origen y a la esencia del PSUC como partido unificado, es decir, como partido marxista de tipo nuevo, mezcla de socialistas y comunistas, que tenían en el antifascismo la bandera que los unía y que definía la política del partido. EI PSUC, pues, no era un partido comunista ni un partido socialista. Era un partido unificado.

Pero quizás lo más sorprendente de esta situación es que la propia organización internacional de los partidos comunistas, la IC, había fomentado el na-

2.800 de la USC, 2.000 del PCC, 1.500 de la FC del PSOE, y 500 del PCP). Y, un tercer caso, ya sensiblemente inferior a la cifra inicial aportada por L. Ponamariova, correspondía a BOLLOTEN, Burnett: La Guerra Civil española: Revolución y contrarrevolución, Madrid 1989, pág. 610, quien hablaba de unos 2.500 militantes (entre 1.200 y 1.500 de la USC, menos de 400 del PCC, entre 600 y 700 de la FC del PSOE y 80 del PCP), aunque, sin embargo, se trata de una cifra excesivamente reducida.

No obstante, ante este abanico de datos, no cabe ninguna duda que las interpretaciones que cuantificaban al alza el número inicial del militantes del PSUC deben cuestionarse, tal y como sucedía, por ejemplo, con el caso de ALCARAZ, Ricard: La Unió Socialista de Catalunya, Barcelona, 1987, pág. 244, quien aseguraba que el PSUC disponía de unos 8.500 militantes en el momento de su nacimiento (4.500 de la USC, 2.000 del PCC, 1.500 de la FC del PSOE y 500 del PCP). 
cimiento del partido unificado catalán a través de la táctica frentepopulista, aprobada en el VII Congreso de la IC (25 de julio-20 de agosto de 1935). Ahora bien, aunque desde la IC se había apostado por la fusión de socialistas y comunistas en un único partido para así hacer frente al fascismo, en el caso del PSUC el planteamiento frentepopulista no fue bien recibido por la IC. Desde Moscú se constataría un fuerte desacuerdo con la composición ideológica del nuevo partido catalán, especialmente al contrastarla con la composición ideológica de los partidos comunistas de Europa occidental agrupados bajo la propia IC.

Así, y en primer lugar, desde las filas de la IC se cuestionaba la elevada presencia de militancia socialista en el PSUC, que representaban más del $55 \%$ del total de militantes del partido catalán, cuando los partidos comunistas de Europa Occidental estaban integrados hegemónicamente, por no decir exclusivamente, por comunistas ${ }^{3}$. Un buen ejemplo de la posición de la IC la expresaba el delegado francés de la IC en España, André Marty. Éste, a mediados de octubre de 1936 escribía el siguiente informe para Iosif Stalin, alertando de la falta de hegemonía comunista en el PSUC fruto de la presencia de un gran número de socialistas, así como de las vinculaciones de un amplio sector del PSUC con el PSOE:

El Partit Socialista Unificat de Catalunya no está amalgamado. Continúa siendo la suma de los cuatro partidos que lo han fundado. Desde el punto de vista comunista, aunque su dirección está en nuestras manos, no tiene una columna vertebral ideológica. Ésto genera considerables oscilaciones (...) Desgraciadamente, la política oscilante del partido, sobretodo en relación a los dirigentes, ha puesto al frente de la UGT catalana a Sesé, un individuo extremadamente sospechoso desde todos los puntos de vista (ver el juicio de la comisión catalana del $7^{\circ}$ Congreso de la IC, septiembre de 1935) (...) La dirección del Partido Socialista de Madrid (Partido Obrero Español) continúa trabajando dentro del PSUC y habitualmente grupos locales le escriben a ella en lugar de escribir al C. C. del PCE. Por otro lado, Caballero se esfuerza por ganarse a la dirección del PSUC 4

$\mathrm{Y}$, en segundo lugar, la IC también cuestionaba abiertamente la presencia de un nacionalismo catalán en el PSUC, que incluso llegaría a plantear durante los primeros meses del conflicto bélico la autodeterminación de Cataluña y, además, manifestaría su voluntad de mantener el PSUC como un partido independiente del PCE. Este planteamiento chocaba frontalmente con la esencia de la IC. No debemos olvidar que esta organización internacional era la abande-

3 Así lo demostraban los casos del PCF y del PCI, los dos partidos comunistas con mayor arraigo social y fuerza política en Europa occidental. Para el primero, véase KRIEGEL, Anne: Les communistes français dans leur premier demi-siècle. 1920-1970, París 1985, págs. 55-62; y, para el segundo, SPRIANO, Paolo: Storia del Partito comunista italiano. I fronti popolari, Stalin, la guerra, Torino 1970 , págs. 7-20.

4 CRCEDHC: Fondo 495, circunscripción 10, caso $n^{\circ}$ 209. MARTY, André: Notas sobre el P.C.E., ¿Madrid? 11/10/36, págs. 2-3. Original en francés.

Hispania, LXII/1, núm. 210 (2002) 259-282 
rada de las luchas sociales, pero no de las nacionales; y que, además, la aparición en escena del PSUC había supuesto que este partido incumpliese uno de los principios en los que se fundamentaba la IC, el dogma leninista de un Estado, un partido, ya que ahora en el Estado español existían dos 'partidos identificados con Moscú, el PCE y el PSUC. Por todo ello no era extraño que desde la IC se llegase a calificar a un buen número de militantes del PSUC como nacionalistas pequeño-burgueses. De hecho, un buen reflejo de este sentimiento lo recogía el informe del delegado argentino de la IC, Vittorio Codovila, elaborado el 13 de octubre de 1936 para la dirección de la IC:

Le parti unifié a cherché à s'emanciper de l'aide politique du parti communiste d'Espagne -malgré qu'il ait adhéré à l'Internationale communiste- à cause de la présence des éléments nationales et socilaistes qui participent dans le nouveau parti et auxquels nos camarades n'ont pas su s'imposer ${ }^{5}$

En definitiva, a pesar que el PSUC desde el mismo instante de su nacimiento se había autoconsiderado adherido a la $\mathrm{IC}^{6}$, ello no impedía que desde esta organización internacional se considerase que la composición ideológica de los militantes del partido catalán era errónea. Aunque el PSUC no era un partido comunista, su adhesión a la IC y el hecho que en él se encontrasen los antiguos militantes de la filial catalana del PCE, había generado la atención de esta última por el partido catalán. Pero como resultado de la adhesión del PSUC a la IC, esta última analizaba a la primera en función de los parámetros que regían la composición ideológica de los partidos encuadrados en la IC. Y, en este caso, tal y como hemos visto, la composición ideológica del PSUC no era equiparable a la de los partidos comunistas encuadrados en la IC. El conflicto, pues, estaba servido.

\section{JULIO 1936-JULIO 1937: El CRECIMIENTO EXPONENCIAL DE UNA MILI- TANCIA ECLÉCTICA IDEOLÓGICA Y SOCIALMENTE}

Si más o menos hemos podido definir el número de militantes del PSUC durante los primeros días de vida del partido y su perfil ideológico, aunque no su perfil social por la inexistencia de datos, para encontrar otra referencia sobre la militancia del PSUC tenemos que esperar a marzo 1937.

5 Citado por ElORZA, Antonio: «El rapto de la Nación: Los comunistas catalanes ante la reivindicación nacionalista» en Le discours sur la nation en Catalogne aux XIXe et XX siècles. Hommage à Antoni M. Badia i Margarit (París) 1 (1997), pág. 75.

6 Durante toda la Guerra Civil Española el PSUC no fue reconocido por la IC como sección nacional de esta organización, sino como partido adherido a la IC, estableciendo su vinculación con la IC a través del PCE. No sería hasta el 7 de julio de 1939 cuando el PSUC sería reconocido por el Comité Ejecutivo de la IC como sección nacional de la IC, tal y como se recoge en: CRCEDHC. Fondo 495 , circunscripción 18 , caso. n 159 . COMITÉ EJECUTIVO DE LA IC: Sin título, Moscú 07/07/39, 3 págs. Original en español. 


\subsection{Julio 1936 -marzo 1937}

Del 5 al 8 de marzo se celebraba en Valencia el Pleno del Comité Central del PCE, durante el cual Joan Comorera y el secretario de relaciones del PSUC, Rafael Vidiella, afirmaron que su partido había alcanzado los 50.000 militantes $^{7}$. Según estos datos, el PSUC, en casi nueve meses de existencia, habría multiplicado por diez su militancia. Aunque muy probablemente se trataba de una cifra exagerada, lo cierto es que entre julio 1936 y marzo 1937 la militancia del partido catalán había experimentado un crecimiento espectacular, exponencial. ¿Qué elementos explicaban esta tendencia, y cuál era la procedencia ideológica y social de los nuevos militantes?

Diversos factores estaban detrás de esta dinámica $\mathrm{y}$, aunque dependían de cada caso particular, generalmente se interelacionaban. Además, a través del análisis de los citados factores podremos aproximarnos, por primera vez, a la procedencia social de los militantes del PSUC, teniendo siempre presente que su perfil social estaba estrechamente ligado con su perfil ideológico.

El primero de esos factores radicaba en las propuestas del PSUC sobre la guerra y la revolución. El partido catalán era favorable a priorizar la primera sobre la segunda, apostando por el establecimiento inmediato de la revolución democrático-burguesa y dejando la revolución proletaria para el futuro, una vez hubiera finalizado la Guerra Civil. Con estas propuestas un buen número de catalanes percibieron el PSUC como un partido revolucionario pero de orden, que se oponía a las propuestas maximalistas de la CNT-FAI (y POUM) favorables a la priorización de la revolución y al establecimiento inmediato de la revolución proletaria. Así, una amplia amalgama de sectores sociales que no se identificaban con el radicalismo revolucionario de la CNT-FAI (y del POUM) se acercaron al PSUC, como el caso de los pequeños propietarios agrícolas y urbanos, y también el de un nutrido número de obreros urbanos y asalariados agrícolas. Estas características sociológicas de los nuevos militantes del PSUC estaban estrechamente ligadas con su procedencia ideológica. Veámoslo.

La atracción del PSUC gracias a sus propuestas sobre la guerra y la revolución fue especialmente importante, cuantitativamente, entre los militantes de la ERC. Así, la ERC, el partido emblemático de la pequeña burguesía catalana, se convirtió en el filón principal de procedencia de los nuevos militantes del PSUC $^{8}$. Las posturas del PSUC sobre la guerra y la revolución se convirtieron en una temática compartida con la ERC, ya que conectaban con el proyecto político y social que había defendido y defendía esta última. Por ello muchos miembros de la ERC vieron en el PSUC una edición renovada, y radicalizada, de los proyectos de la propia ERC. Además, el fuerte proceso de desintegración

7 Treball, $\mathrm{n}^{\circ} 197,07 / 03 / 38$, pág. 5.

8. Entre los ejemplos más significativos encontramos a cuadros destacados de la ERC como Josep Antoni Trabal, Pere Foix o Lluís Aymamí i Baudina.

Hispania, LXII/1, núm. 210 (2002) 259-282 
interna que estaba sufriendo la ERC facilitaba que un buen número de sus militantes tuviesen que integrarse en otra organización para poder hacer frente, con garantías, a los proyectos y a las propuestas de la CNT-FAI (y del POUM). $\mathrm{Y}$ aquí, el PSUC se convirtió, de nuevo, en el principal punto de destino de los miembros de la ERC.

Pero la atracción del PSUC entre los militantes de la ERC no se ciñó únicamente a la propia ERC, sino también a aquellas organizaciones que estaban bajo la esfera de ésta, mereciendo especial atención dos colectivos. Uno de ellos, las juventudes de la ERC, creadas en mayo 1936 bajo el nombre de JEREC. El 4 de agosto de 1936 el portavoz de la dirección del PSUC, el periódico Treball, se hacía eco del ingreso de miembros de las JEREC en el PSUC ${ }^{9}$. La mayoría de los militantes de estas juventudes pasaban a integrar las filas del PSUC, ya que consideraban obsoleto el proyecto de los partidos republicanos (entre ellos el de la propia ERC) para defender a la República y veían en el PSUC a la organización que, sintonizando con el proyecto político, social y económico de las JEREC, estaba mejor vertebrada para conseguir la victoria sobre los militares sublevados. Desde la óptica del PSUC el ingreso de las JEREC era un ejemplo a seguir para luchar por la liberación nacional y social de Cataluña, pero lo más importante era que, con este ejemplo, el partido catalán había abierto sus puertas a todas aquellas organizaciones y/o individuos que se sintiesen identificados con su proyecto sobre la guerra y la revolución.

$Y$ si el caso de las JEREC era significativo, no lo era menos el del Sindicat de Funcionaris de la Generalitat de Catalunya, la agrupación sindical que integraba a la gran mayoría de funcionarios de la Generalitat de Catalunya. Los integrantes de esta agrupación sindical se pasaron en bloque al PSUC, lo que supuso un importante número de incorporaciones a este partido, ejemplo que a inicios de agosto 1936 también se había producido en la FNEC, el sindicato universitario más importante de Cataluña.

Así, pues, aunque el PSUC incrementó notablemente su base militante gracias al ingreso de un buen número de integrantes de la ERC y de las organizaciones que estaban bajo la esfera de ésta, con ello también aumentó la heterogeneidad de su militancia, tanto a nivel ideológico como social. Ahora, ideológicamente, el PSUC ya no era sólo un partido mezcla de socialistas y comunistas (muchos de los cuales eran, al mismo tiempo, nacionalistas), sino también una organización donde se integraban sectores procedentes del ámbito liberal progresista; y, socialmente, la llegada de militantes de la ERC y de las organizaciones bajo su esfera había supuesto el ingreso de un amplio número de pequeños propietarios agrícolas y urbanos, así como asalariados agrícolas.

Sin embargo, la heterogeneidad ideológica y social de los militantes del PSUC no se incrementó sólo por la presencia de antiguos militantes de la ERC

9 Treball, $\mathrm{n}^{\circ}$ 12, 04/08/36, pág. 1. De los dirigentes más relevantes de las JEREC que pasaron a engrosar las filas del PSUC cabe resaltar a Jaume Vàchier, Antoni Perramon y Marià Sabaté. 
o de organizaciones bajo la esfera de ésta. La propuesta del PSUC sobre la guerra y la revolución también generó el ingreso de militantes de Estat Català, de los sindicatos mercantiles, de anarquistas e incluso de comunistas leninistas. Respecto al partido independentista Estat Català, el PSUC mantuvo una política de acercamiento que encontró el apoyo del núcleo dirigente de esta organización y que, en algunos casos, incluso llegó a militar en el PSUC. En el caso de los sindicatos mercantiles, el PSUC consiguió un conjunto de incorporaciones masivas procedentes del CADCI, un sindicato con amplio arraigo en el mundo mercantil catalán que, iniciada la Guerra Civil, se integró en la UGT catalana y, a través de ella, en el PSUC. Y, finalmente, respecto al mundo anarquista y al comunismo leninista, el PSUC atrajo a algunos pocos militantes de la CNTFAI y del POUM, ofreciéndoles una opción que, dentro del espíritu revolucionario de aquellos días, se distanciaba del radicalismo de la revolución proletaria, aunque sin renunciar a su aplicación en un futuro. Dentro de esta línea mereció especial atención la campaña para atraerse a militantes del POUM, bajo la teorización que la militancia poumista era una militancia sana, que simplemente debía liberarse de la degeneración y los errores de su dirección.

Con toda esta amalgama de incorporaciones, el PSUC incrementaba la heterogeneidad ideológica y social de sus militantes. Ideológicamente, a su base originaria había añadido militantes de partidos liberales progresistas, de organizaciones anarquistas y de un partido comunista leninista; y, socialmente, a la definición del PSUC como partido obrero se le habían añadido pequeños propietarios agrícolas y urbanos, así como sectores procedentes de las profesiones liberales y asalariados agrícolas. El PSUC, pues, se confirmaba como un partido paraguas donde tenían cabida militancias de diferentes procedencias políticas y sociales, pero todas ellas con el nexo común de la identificación con el proyecto del PSUC sobre la guerra y la revolución.

Pero el resto de factores que estaban detrás del crecimiento del número de militantes del PSUC también reproducían las pautas de heterogeneidad social y, especialmente, de heterogeneidad ideológica, que había generado las propuestas del PSUC sobre la guerra y la revolución. Así, el segundo factor que explicaba el crecimiento del número de militantes del PSUC entre julio 1936 y marzo 1937 se encontraba en la vinculación de este partido con la UGT de Cataluña. Esta última, sindicato de la FC del PSOE, se convirtió en la organización sindical del PSUC desde el mismo momento que la FC del PSOE se fusionó en el PSUC. A partir de ese instante se estableció una estrecha relación entre ambos, sin ningún tipo de fisuras, que perduró durante toda la Guerra Civil $^{10}$, llegando al extremo que militantes de la UGT catalana crearon el PSUC en aquellas localidades donde no existía ninguno de los cuatro partidos

10 Véase BALLESTER, David: Els anys de la guerra. La UGT de Catalunya (1936-1939); Barcelona 1998, págs. 115-126.

Hispania, LXII/1, núm. 210 (2002) 259-282 
que teóricamente tenían que formar el PSUC ${ }^{11}$. Así las cosas, un buen número de militantes de la UGT catalana se convirtieron, en el ámbito político, en militantes del PSUC. Esta dinámica se acentuó a partir del 27 de agosto de 1936, cuando la Generalitat de Cataluña aprobó el Decreto de Sindicación Obligatoria que permitió, según datos oficiales de la propia UGT (sobredimensionando las cifras reales), que este sindicato pasase de tener 86.000 afiliados en agosto 1936, a tener 141.000 en septiembre 1936 y 436.209 en octubre del mismo año ${ }^{12}$. Entre los nuevos afilados a la UGT una buena parte también se afilió al PSUC, aunque no disponemos de cifras concretas. Lo importante, pero, es que con ello se acentuó la heterogeneidad ideológica de la militancia del PSUC, ya que entre aquellos que procedían de la UGT catalana había socialistas, pero también liberales de izquierdas (que habían entrado a militar en la UGT porque veían en ella la única alternativa sólida a los proyectos de la CNT) y algunos comunistas leninistas (fruto del ingreso de la organización sindical del POUM, la FOUS, en la UGT catalana en septiembre 1936). Este cóctel era una aberración para la IC, muy especialmente en el caso de los integrantes de la FOUS, ya que, como es sabido, Moscú consideraba el POUM como su enemigo trotsquista en España.

Otro factor que explicaba el fuerte incremento del número de militantes del PSUC entre julio 1936 y marzo 1937 se encontraba en las ventajas que suponía para la población civil la posesión del carnet de militante de un partido o sindicato del bando republicano. Ésto beneficiaba por igual al conjunto de organizaciones republicanas, de las que el PSUC no quedaba al margen. La posesión del mencionado carnet era una acreditación y una garantía para su propietario de ser antifascista, y ello se traducía en garantías de seguridad personal (ya que difícilmente se cuestionaría su compromiso con la causa antifascista) y en facilidades para poder acceder a los productos de primera necesidad.

Pero en el incremento de la militancia del PSUC también tuvo un papel decisivo la atracción que este partido ejerció sobre un amplísimo sector de lo que podríamos llamar, en términos sociales, como clases medias: la intelectualidad catalana (escritores, dibujantes...). Se trataba de un colectivo que, sin ser propiamente comunista o socialista (excepto algunos casos muy concretos), pasaba a militar, identificarse y/o comprometerse con el PSUC, ya que consideraban que era un partido con una excelente organización, que defendía sus mismas posturas sobre la guerra y la revolución, y que se distanciaba del radicalismo de la CNT-FAI (y del POUM). El hecho de que una buena parte de esta intelectualidad militase en el PSUC era importante numéricamente, pero aún era más significativo el prestigio que proporcionaban al PSUC, gracias a la

11 Un ejemplo emblemático lo constituye la localidad de Igualada. Véase: TÉRmENS, Manel: Revolució i Guerra Civil a Igualada (1936-1939), Barcelona 1991, pág. 53.

12 Estos datos fueron recogidos por GABRIEL, Pere: «Sindicalismo y sindicatos socialistas en Cataluña. La UGT, 1888 - 1938» en Historia Social (Valencia) 8 (1990) pág. 66. 
incidencia y a la influencia que tenían entre la población catalana. Desde el prisma del PSUC los intelectuales jugaban un papel vital en la vida de la retaguardia republicana y del frente, porque además de ser un ejemplo a seguir por parte de los ciudadanos, les atribuían un papel de primer orden en la educación y la formación cultural/intelectual de la población. Para conseguir la atracción de los intelectuales el PSUC utilizó, especialmente, un conjunto de publicaciones que gozaban de notable difusión dentro de la sociedad catalana, como L'Esquella de la Torratxa, Papitu y Mirador.

A todo ello, también hay que añadir entre los factores que estaban detrás del incremento numérico de la militancia del PSUC el limitado nivel de concienciación política y de formación ideológica de un amplio sector de la población catalana, tal y como lo han demostrado los estudios de historia oral y las memorias de antiguos militantes del partido ${ }^{13}$. Estas últimas permiten apreciar cómo muchos miembros del PSUC entraban a militar sin saber prácticamente cuál era la esencia de esta organización, sus características más relevantes y su espectro ideológico, aunque ésta no era una dinámica exclusiva del PSUC, sino del conjunto de las organizaciones políticas y/o sindicales catalanas durante los años de la guerra ${ }^{14}$.

Finalmente, el último elemento que estaba detrás del aumento de la militancia del PSUC residía en la capacidad de este partido para presentarse a la sociedad catalana como el único y legítimo representante de la URSS en Cataluña. El país de los soviets era un mito en la Europa del momento, de la cual España, y en particular Cataluña, no quedaban al margen ${ }^{15}$. Por ello, que el PSUC se presentase a la población catalana como el representante de la URSS en Cataluña le confería el honor y el prestigio de ser el representante del país dónde se había llevado a cabo la primera revolución comunista de la historia de la humanidad, del país que estaba implicado profundamente en la lucha contra el fascismo, y que ayudaba militar y alimentariamente a la Cataluña republicana. Estos argumentos, especialmente el último, tuvieron un papel decisivo para generar la atracción del PSUC entre un buen número de catalanes.

13 Véase Monjo, Anna y VegA, Carme: Els treballadors i la Guerra Civil. Història d'una indústria catalana col-lectivitzada, Barcelona, Empúries, $1986+211$ págs.; PÀMIES, Teresa: Quan érem capitans, Barcelona, Proa, $1984+174$ págs.; VILANOVA, Mercedes: Les majories invisibles. Explotació fabril, revolució i repressió, Barcelona, Icària, $1995+487$ págs.

14 Un ejemplo significativo, referido al caso concreto del POUM, lo recoge LANGDON-DAviES, John: La Setmana Tràgica de 1937. Els fets de maig $i$ altres vivències de la guerra civil a Catalunya, Barcelona 1987, pág. 25: "Va arribar el 19 de juliol $i$ davant la sorpresa de tothom, el verdulaire va saber que era un revolucionari i que s'bavia afiliat al POUM, el grup antistalinista. És difícil de creure que bagués aprofundit en les seves lectures per a convèncer-se que Stalin bavia tragiversat Marx $i$ Lenin» (TRADUCCIÓN: «Llegó el 19 de julio y ante la sorpresa de todos, el verdulero supo que era un revolucionario y que se babía afiliado al POUM, al grupo antiestalinista. Se bace difícil pensar que bubiese profundizado en sus lecturas para convencerse de que Stalin babía tragiversado a Marx y Lenin»).

15 Un excelente estudio sobre el mito de la URSS en Cataluña se encuentra en MAYAYO, Albert: «El mite de l'URSS en el moviment nacionalista català: revolució i autodeterminació (19171989)» en Miscel-lània d'bomenatge a Josep Benet (Barcelona) (1991) págs. 331-350.

Hispania, LXII/1, núm. 210 (2002) 259-282 
En definitiva, el crecimiento del PSUC entre julio 1936 y marzo 1937 fue el resultado de un conjunto de factores internos al propio partido (su concepción sobre la guerra y la revolución, la vinculación con la UGT catalana, la política de atracción de la intelectualidad catalana republicana, y la capacidad del PSUC para aparecer a la opinión pública como el representante de la URSS en Cataluña); y de factores externos, derivados de la propia dinámica que vivía la Cataluña del momento (la importancia de tener el carnet de alguna organización antifascista y el bajo nivel de formación ideológica y política de la gran mayoría de la población). Esta diversidad de elementos se traduciría en una amplia variedad de procedencias ideológicas y sociales entre los nuevos militantes. El resultado final sería el incremento de la heterogeneidad de la militancia del PSUC, tanto a nivel ideológico como social. En el aspecto ideológico, en el PSUC habían confluido desde comunistas leninistas (procedentes del POUM) y anarquistas (procedentes de la CNT-FAI) hasta liberales progresistas (procedentes de la ERC y las organizaciones bajo la esfera de ésta), pasando por socialistas (procedentes de la UGT catalana) e incluso nacionalistas de corte independentista (procedentes de Estat Català). Y, a nivel sociológico, además de las incorporaciones de obreros, en el PSUC habían ingresado pequeños propietarios urbanos y agrícolas, así como sectores de profesiones liberales y asalariados agrícolas. Sin ningún tipo de dudas, la composición sociológica y, muy especialmente la composición ideológica de los militantes del PSUC, no seguía los parámetros de los partidos comunistas europeos occidentales.

¿Cuál sería la reacción de la IC ante esta heterogeneidad ideológica y social de la militancia del PSUC? Desde esta organización internacional se dejarían oír fuertes críticas a la composición del PSUC, especialmente en su vertiente ideológica, ya que ésta era la que generaba un mayor contraste en relación con la composición de los partidos comunistas de Europa occidental. Y es que el PSUC no tenía una base militante como la de los partidos comunistas de Europa occidental ligados a Moscú, especialmente en su vertiente ideológica, y, lo que era aún peor, esta tendencia se había incrementado durante los primeros meses de la Guerra Civil. Así lo reconocería el delegado francés de la IC, André Marty, en un informe elaborado el 7 de marzo de 1937, dónde lacónicamente aseguraba que "dentro del partido hay elementos honrados, pero también muchos otros están lejos de nosotros» ${ }^{16}$.

\subsection{Marzo 1937-julio 1937}

Con este estado de la cuestión se llegaba a julio 1937, fecha de celebración de la $1^{\text {a }}$ Conferencia Nacional del PSUC. Si en marzo 1937 las fuentes oficiales

16 CRCEDHC: Fondo 495, circunscripción 74, caso $n^{\circ}$ 206. MARTY, André: El problema espa$\tilde{n} o l$, ¿Barcelona? 07/03/37, pág. S. Original en ruso.

Hispania, LXII/1, núm. 210 (2002) 259-282 
del partido hablaban de unos 50.000 militantes, estas mismas ahora los cifraban en $60.000^{17}$. Aunque esta última cifra estaba sobredimesionada, y muy probablemente se debería ubicar en unos cinco mil militantes menos, no encubría que entre marzo y julio de 1937 había continuado la dinámica de crecimiento exponencial del partido.

Los factores que estaban detrás del crecimiento respondían a los mismos parámetros que habíamos visto para el período julio 1936-marzo 1937, aunque a ellos ahora se añadían un par de elementos nuevos, fruto de las consecuencias de los Sucesos de mayo de 1937 en Cataluña. En primer lugar, a raíz de aquellas jornadas el PSUC se convirtió en la principal fuerza política de Cataluña, lo que le sirvió para facilitarle la atracción de militantes en tanto que organización hegemónica en Cataluña; y, en segundo lugar, la incidencia y la injerencia de la URSS en la vida catalana (al igual que en el resto del territorio republicano) había crecido exponencialmente después de mayo 1937, y el PSUC lo aprovechó para rentabilizar aún más su identificación con la URSS.

Sin embargo, en la continuidad del crecimiento del número de militantes del PSUC entre marzo-julio 1937 se apreciaba una variación respecto al perfil ideológico y social expuesto entre julio 1936-marzo 1937: en el perfil social ya no se conseguía el incremento a través de los pequeños propietarios urbanos y agrícolas, sino a través de los obreros industriales y campesinos asalariados ${ }^{18} ; \mathrm{y}$, respecto al perfil ideológico, los nuevos militantes ya no procedían, mayoritariamente, de los partidos liberales progresistas, es decir, de la ERC y de las organizaciones que estaban bajo la esfera de esta última. La atracción procedente de este colectivo había tenido su apogeo durante la segunda mitad de 1936, aprovechando las urgencias de numerosos militantes de la ERC (y de las organizaciones bajo la esfera de ésta) para encontrar una alternativa a la desvertebración de su partido. Pero a partir del primer tercio de 1937 esta fuente se secó rápidamente.

Precisamente es a partir de julio 1937 cuando podemos aproximarnos con mayor precisión a la composición sociológica de los militantes del PSUC, a partir de los datos presentados por el secretario de organización del partido catalán durante la $1^{\text {a }}$ Conferencia Nacional del PSUC. Así, según Miquel Valdés el $62 \%$ del total de militantes del PSUC estaba compuesto por obreros industriales, el $20 \%$ por campesinos trabajadores (sin especificar si se trataba de pequeños propietarios o asalariados agrícolas), el $16 \%$ por asalariados no industriales (maestros, dependientes de comercio y de industria...) y el $2 \%$ por pequeña burguesía ${ }^{19}$.

17 Treball, $\mathrm{n}^{0} 320,29 / 07 / 37$, pág. 6.

18 Así lo afirmaba el secretario de organización del PSUC, Miquel Valdés, en su informe recogido en Treball, $\mathrm{n}^{\circ} 320,29 / 07 / 37$, pág. 8.

19 Ibid.

Hispania, LXII/1, núm. 210 (2002) 259-282 
Si hacemos caso de estas cifras, la composición social del PSUC era relativamente similar a la composición social del PCE, tal y como lo revelan los datos aportados por la dirección del PCE en marzo de $1937^{20}$. Aunque en este último caso no se presentaban las cifras en tantos por ciento, a diferencia de los datos del PSUC, sino en cifras absolutas, se apreciaba que la composición social de ambos partidos era similar: 1) En el PSUC y en el PCE había una notable presencia obrera, más acentuada en el caso del partido catalán, debido a que en Cataluña existía una mayor proporción de población obrera que en el resto del territorio republicano español; 2) la presencia de pequeños propietarios agrícolas y de asalariados agrícolas era importante en los dos partidos, aunque más numerosa en el caso del PCE debido a que en Cataluña había un menor proporción de población rural en comparación con el resto del territorio republicano; 3) las clases medias (incluyendo a los intelectuales) tenían una presencia significativa en los dos partidos; 4) las mujeres, presentadas en los datos oficiales del PSUC y del PCE como un colectivo propio, en ambos casos representaban menos del $10 \%$ de la militancia total.

Esta similitud en el perfil sociológico de los militantes del PSUC y del PCE implicaba que el PSUC tuviese una composición social similar a la de uno de los partidos comunistas de Europa occidental miembro de la IC. Pero esta similitud era el resultado de una situación excepcional, que no se reproducía en ninguno de los otros partidos comunistas de Europa occidental, generada por la coyuntura de una guerra: la Guerra Civil Española. Durante el conflicto bélico, tanto el PSUC como el PCE defendieron la misma política frentepopulista, de la cual su eje más significativo eran las posturas de los dos partidos sobre la guerra y la revolución. A través de la política frentepopulista PSUC y PCE habían atraído a sus filas a obreros, pero también a pequeños propietarios agrícolas y urbanos, clases medias y asalariados agrícolas que veían en estos dos partidos una organización revolucionaria pero de orden, alejada del radicalismo de la CNT-FAI (y del POUM).

La afirmación de que la composición social del PSUC y del PCE era fruto de una situación coyuntural (la Guerra Civil Española) y no de una dinámica estructural, se confirma si realizamos una comparación del perfil socioprofesional de la dirección de ambos partidos. Mientras que en entre los integrantes de la dirección del PSUC el $70 \%$ eran trabajadores del sector servicios, el $28 \%$ trabajadores manuales y un $2 \%$ tenían un perfil socio-profesional des-

20 Estos datos se encuentran en el Archivo Histórico del Comité Céntral del PCE, Film XVI. Según este documento, en marzo de 1937 la militancia del PCE estaba integrada por 87.660 obreros industriales; 62.250 obreros agrícolas, 76.700 campesinos, 15.485 clases medias, 7.045 intelectuales, 19.300 mujeres y 151.600 militares. Obsérvese, no obstante, la dificultad que existe para poder comparar con total exactitud algunos datos aportados por el PSUC y por el PCE por la falta de coincidencia y equivalencia en relación al grupo social que se hace constar. Un ejemplo se encuentra en el caso de la presencia rural en el PSUC y PCE, presentada en el primer caso como campesinos trabajadores y, en el segundo, como obreros agrícolas y como campesinos. 
conocido, en el PCE estas cifras se distribuían de forma prácticamente inversa. Entre los dirigentes del PSUC encontrábamos a maestros (Joan Comorera, Víctor Colomer, Dolors Piera), dependientes mercantiles (Lluís Álvarez, Pere Aznar, Wenceslao Colomer, Miquel Serra Pàmies), dependientes de banca (Josep Muni), vendedores de libros y cajistas de imprenta (Rafael Vidiella) y peritos agrónomos (Joaquín Almendros); mientras que los que tenían un perfil de trabajadores manuales u obreros representaban un número mucho menor (Pere Ardiaca, Artur Cussó, Josep del Barrio, Felip García Mates y Miquel Valdés), sin olvidar la presencia de un campesino (Josep Torrents) ${ }^{21}$. En cambio, en la dirección del PCE predominaban los dirigentes procedentes del ámbito obrero y de los trabajos manuales, siendo un claro ejemplo el propio secretario general, José Díaz, un antiguo panadero; y la número dos del partido, Dolores Ibárruri, que procedía de una familia minera.

El amplio espectro de procedencias socio-profesionales de los integrantes de la dirección del PSUC estaba estrechamente relacionado con la diversidad social e ideológica del partido. La diversidad definía a la dirección del PSUC, pero también a su propia base militante, dibujando unas características diferentes a la de los partidos comunistas de Europa occidental, fundamentalmente en el caso de la composición ideológica. No obstante, en el aspecto social también existían algunas diferencias, tal y como lo demuestra la comparación del perfil social de los militantes del PSUC con el de uno de los grandes partidos comunistas de Europa occidental, el PCF.

El PCF era uno de los partidos emblemáticos de la IC, tanto por su fuerza política y arraigo social, como por su estrecha vinculación con Moscú. Según los datos expuestos en su VI Congreso (31 marzo-6 abril de 1937) tenía alrededor de un $56 \%$ de obreros, un 20 '21\% de clases medias y un $3.41 \%$ de funcionarios y gente de servicios públicos ${ }^{22}$. Entre 1929 y 1937/38 el PCF sufrió un incrementó exponencial de la presencia obrera, que convirtió a esta clase social en la protagonista del incremento de la militancia. Un ejemplo relevante de esta dinámica lo proporcionaba la región parisiense, donde el PCF pasó de tener 9.080 obreros en 1933 , a 115.367 en 1937 , lo que representaba un incremento del $1.270 \%^{23}$. Si hacemos extensibles estas cifras al conjunto de la militancia del PCF, en 1937 tendríamos que hablar de un 80/85\% de presencia obrera entre sus militantes, cifra que contrastaba sensiblemente con el $62 \%$ de militantes obreros que tenía el PSUC en julio 1937.

Pero en el juego de las comparaciones entre el perfil de los militantes del PSUC y el de los partidos comunistas de Europa occidental sorprendía, aparentemente, la coincidencia de las cifras de la presencia femenina, que en todos los

\footnotetext{
21 UCELAY, Enric: «Socialistas y comunistas en Cataluña durante la Guerra Civil: Un ensayo de interpretación», en Anales de Historia de la Fundación Pablo Iglesias (Madrid) 1 (1987) pág. 319.

22 Cifras recogidas por KRIEGEL, Anne: Les communistes français..., op. cit., pág. 89.

23 Ibid.

Hispania, LXII/1, núm. 210 (2002) 259-282
} 
partidos eran presentadas como un colectivo propio. En julio 1937 las mujeres representaban el $5 \%$ del total de los militantes del PSUC ${ }^{24}$, mientras que en el PCE el $7{ }^{\prime} 1 \%$ en marzo $1937^{25}$, y en el PCF alrededor del 4/5\% en $1937^{26}$. No obstante, la presencia femenina en el PSUC tenía su propia lógica e idiosincrasia.

Desde el nacimiento del partido catalán las mujeres habían tenido cabida en el PSUC. Disponían tanto de una secretaria propia como de una Secretaría femenina en el Comité Ejecutivo-Central, la cuál se encargaba de dirigir la temática femenina y que desde la remodelación del Comité Ejecutivo-Central en agosto 1936 estaba en manos de una mujer. Ahora bien, ésto no significaba que las mujeres tuviesen un papel relevante en la dirección del partido, ya que cuando el PSUC pensaba en términos de participación femenina lo hacía siempre en términos de base militante. No obstante ésto no ocultaba que en el PSUC existía una firme voluntad para conseguir una notable presencia femenina, bien por motivos ideológicos, bien por motivos estratégicos:

a) El PSUC se presentaba como un partido que quería acabar con la opresión que había existido en la sociedad catalana hasta esos instantes, y ello pasaba por acabar con la opresión que sufría la mujer. Si el partido catalán quería cambiar la situación de este colectivo dentro de la sociedad catalana, era lógico que ésta tuviese representación en las filas del PSUC;

b) el PSUC, al nacer como un partido marxista de tipo nuevo, que quería superar la tradicional división del marxismo catalán, también aspiraba a acabar con la tradicional escasa presencia de la mujer dentro de la vida política catalana;

c) las mujeres eran un grupo social muy atractivo, ya que englobaban, aproximadamente, el $50 \%$ de la población de Cataluña, además de que estaban adquiriendo una progresiva importancia en la retaguardia catalana, ocupando los lugares que los hombres dejaban vacantes para ir al frente. Por ello, si el PSUC deseaba tener influencia social (y política) en la retaguardia catalana tenía que atraer a sus filas a buena parte de este colectivo.

24 Treball, $\mathrm{n}^{\circ} 318,27 / 07 / 37$, pág. 7.

25 Treball, $\mathrm{n}^{\circ} 320,29 / 07 / 37$, pág. 6.

26 En el caso del PCF no disponemos de ningún dato concreto para el período 1936-1939. La primera cifra documentada corresponde al 1946 , donde el colectivo femenino representaba el 11'2\% del total de la militancia, tal y como recogió KRIEGEL, Anne: Les communistes français..., op. cit., pág. 78. Si en 1946 la presencia femenina llegaba al 11'2\%, parece lógico pensar que diez años atrás, alrededor de 1937, esta cifra sería sensiblemente menor, ya que la participación femenina en el PCF fue creciendo con el paso del tiempo, como lo indica la evolución de las cifras de presencia femenina en el Comité Central del partido a partir de 1936, momento en el cual esta cifra era del 2'2\%, y pasó a ser del 11'5\% en 1945. Véase KRIEGEL, Anne: Les communistes français..., op. cit., pág. 82. 
Entre julio 1936 y enero 1937 el número de mujeres afiliadas al PSUC fue paupérrimo, aunque no disponemos de cifras concretas. Sin embargo, a partir de febrero 1937 esta dinámica cambió. La presencia femenina cogió un fuerte impulso, apoyada en la campaña de la Secretaría femenina para atraer a este colectivo. No obstante, el incremento del colectivo femenino nunca llegaría, ni se acercaría, a las cotas del $50 \%$ del total de la militancia del PSUC, tal y como deseaba la Secretaría femenina del partido.

\section{AGOSTO 1937-FEBRERO 1938: El CRECIMIENTO A LA BAJA DE UNA MILI- TANCIA QUE MANTIENE SU ECLECTICISMO IDEOLÓGICO Y SOCIAL}

Después de julio 1937 la militancia del PSUC siguió incrementándose, pero con una tendencia a la baja respecto al crecimiento exponencial que había tenido desde julio 1936. Sin ningún tipo de dudas se había truncado el incremento exponencial que había caracterizado la trayectoria del PSUC desde el inicio de la guerra. Sirva como ejemplo que entre julio 1937 y enero 1938 el partido recibió poco más de dos mil nuevas incorporaciones en la retaguardia, y que durante enero 1938 el número total de militantes, entre el frente y la retaguardia, no superó los $60.000^{27}$. ¿Cómo se explicaba esta dinámica, cuando precisamente el PSUC era el principal partido de la vida política catalana y la incidencia del factor soviético en Cataluña era cada vez más intenso?

El factor principal que estaba detrás de esta situación se encontraba en la pérdida del alud de afiliaciones políticas y/o sindicales que había caracterizado a la población catalana durante el primer año de guerra, especialmente durante los seis primeros meses del conflicto bélico. Las ilusiones y las esperanzas que había generado el estallido de la Guerra Civil se había perdido, y ésto había supuesto un notable freno para el incremento de las afiliaciones políticas y/o sindicales. Además de ese factor principal, también jugó su papel el hecho de que la evolución del conflicto bélico estuviese siendo muy negativa para los intereses del bando republicano, la cual cosa generó una disminución de la euforia y las expectativas de victoria que afectó negativamente a la moral de la población y a los estímulos para su movilización política y/o sindical. Y finalmente, el último factor que estaba detrás de la disminución del crecimiento exponencial del PSUC, se encontraba en la progresiva erosión del origen del PSUC como partido unificado, situación que generó reticencias entre sectores de población que no se identificaban con un partido que empezaba a perder la

27 Cifras aportadas por Miquel Valdés y Joan Comorera en los respectivos informes inéditos que elaboraron para la reunión del Comité Central del PSUC en enero 1938. Para el primero, véase CRCEDHC: Fondo 495, circunscripción 10 a, caso $n^{\circ} 228$. VALDÉs, Miquel: Materials per al Comitè Central, Lleida 16/01/38, págs. 2-3, original en catalán; y para el segundo, CRCEDHC: Fondo 495, circunscripción 10 a, caso $\mathrm{n}^{\circ}$ 228. COMORERA, Joan: Apunts per a la reunió del Comité Central, Lleida $16 / 01 / 38$, pág. 1 , original en catalán.

Hispania, LXII/1, núm. 210 (2002) 259-282 
originalidad y el eclecticismo que lo había caracterizado desde su nacimiento. Este aspecto, no obstante, merece un punto aparte.

Entre julio y octubre de 1936 el PSUC se había consolidado como un partido unificado, es decir, como un partido marxista de tipo nuevo, mezcla de socialistas y comunistas, que tenían en el antifascismo la bandera que los unía y que definía la política del partido. Ello había sido posible, en gran medida, gracias a que durante estos meses el PSUC escapó al control y a la incidencia de la IC (y del propio PCE), fruto del desorden generado en el conjunto del territorio republicano por el inicio de la Guerra Civil y la casi independencia que acompañó a Cataluña con el inicio del conflicto bélico. Pero a partir de octubre de 1936 el interés de la URSS por la guerra de España, a raíz de las consecuencias que ésta podía tener en la redistribución de fuerzas en el continente europeo, llevaron a la IC a actuar decididamente sobre territorio español. En el caso de la región catalana esta decisión se tradujo en una ofensiva para incidir en el PSUC, con el objetivo de acabar con la excepcionalidad que tenía este partido para Moscú: había que convertirlo en un partido comunista y, además, hacer de él la obediente filial del PCE en Cataluña. Ahora bien, aunque entre octubre 1936 y mayo de 1937 la IC no alcanzaría este objetivo, debido a la casi independencia de Cataluña (que continuaba dificultando la incidencia de la IC sobre Cataluña) y a la voluntad mayoritaria de los militantes del PSUC de mantener el partido catalán como un partido unificado, se iniciarían los primeros contactos entre la IC y el PSUC. Con este estado de cosas se llegaba a los Sucesos de mayo de 1937, a raíz de los cuales quedó eliminada la casi independencia de Cataluña y se produjo la llegada de la dirección del PCE a la capital catalana, situación decisiva para permitir que la IC (y el PCE) incidiese de forma efectiva sobre el PSUC. A partir de este instante el partido catalán se vio presionado de forma efectiva por la IC (con ayuda del PCE), y el primer resultado fue el inicio de la erosión del carácter del PSUC como partido unificado, antesala del inicio de su conversión en un partido comunista ${ }^{28}$.

Volviendo a la composición de la militancia del PSUC entre agosto 1937febrero 1938, desde la perspectiva de la historia social las cifras de crecimiento de los militantes del PSUC entre julio 1937 y enero 1938 son jugosas y, además, pueden desglosarse. Durante estos meses, en 27 comarcas y 1 subcomarca catalana habían habido 3.295 ingresos, de los cuales, según los datos oficiales, el $40{ }^{\prime} 84 \%$ eran obreros, mientras que el $42{ }^{\prime} 18 \%$ eran campesinos (sin especificar si se trataba de pequeños propietarios agrícolas o de asalariados agrícolas), el $83 \%$ empleados, el $4^{\prime} 4 \%$ intelectuales o gentes de profesiones liberales y el $4{ }^{\prime} 1 \%$ pequeños comerciantes ${ }^{29}$. Esta misma proporción de presencia obrera se

28 Para tratar con más detalle este proceso, véase: PUIGSECH, Josep: El Partit Sacialista Unificat de Catalunya..., op. cit., págs. 28-69.

29 Así lo exponía Miquel Valdés en el informe que preparaba para la reunión del Comité Central en enero 1938. Fuente: CRCEDHC: Fondo 495, circunscripción 10 a, caso $n^{\circ} 228$. VALDÉs, Miquel: Materials..., op. cit., pág. 3. 
reproducía en el caso de Barcelona ciudad, ya que de los 1.421 nuevos militantes el 43 '2\% eran obreros, el 44' $19 \%$ empleados, el 2'5\% campesinos (sin especificar, nuevamente, de qué tipo de campesinos se trataba), el 0 '4\% pequeños comerciantes, el $1^{\prime} 1 \%$ gente de su casa y el $0^{\prime} 42 \%$ sin especificar ${ }^{30}$. En el caso concreto de las cifras de la capital catalana también disponemos de datos sobre la procedencia ideológica de los nuevos militantes: 49 del PCE, 100 de las juventudes del PSUC (las JSUC), 16 de Estat Català, 91 de ERC, 22 del PSOE, 106 de la CNT, 959 de la UGT y 351 de otra central sindical sin especificar ${ }^{31}$.

Estas cifras revelaban, nuevamente, el carácter ecléctico de la composición de los militantes del PSUC, tanto en el aspecto ideológico como social. Nuevamente, pues, el perfil de los militantes del PSUC se distanciaba de las características de la militancia de los partidos comunistas europeos occidentales (excepto en el caso ya comentado del PCE), especialmente desde su vertiente ideológica. Ahora bien, a la IC le quedaba el consuelo de las expulsiones que se habían llevado a cabo en el PSUC durante septiembre 1937, teniendo como blanco a aquellos militantes sospechosos de actos de indisciplina y/o manifestaciones de infidelidad a la causa y a la política del partido, que permitían apreciar en ellas a expulsiones con matiz político-ideológico que en un futuro cercano deberían aumentarse notablemente. De hecho, éstas eran las primeras expulsiones de militantes de base de las que tenemos constancia, y que afectaron a un total de seis militantes ${ }^{32}$.

Respecto al colectivo femenino, entre julio 1937 y enero 1938 se había conseguido el ingreso de 700 mujeres. Esta cifra era insuficiente si tenemos presente las expectativas que había marcado la Secretaría femenina del PSUC sobre el crecimiento que debía seguir este colectivo; pero también era insuficiente en relación con el aumento del protagonismo de la mujer dentro de la retaguardia catalana, tanto en la esfera económica como en la política y la social. Por todo ello, la Secretaría femenina inició una campaña para crear, entre enero y marzo 1938, agrupaciones femeninas del PSUC en todas las localidades catalanas, aunque su éxito no fue el esperado.

\section{MARZO 1938-FEBRERO 1939: HACIA UNA MILITANCIA IDEOLÓGICAMENTE COMUNISTA, Y SOCIAI:MENTE OBRERA}

Así se llegaría a finales de marzo 1938, momento en el cual el PSUC iniciaría el proceso de conversión en un partido comunista, sellada entre enero y

\footnotetext{
30 Ibid.

31 Ibid.

32 Los afectados fueron Hermenegild Benavent (Treball, $\mathrm{n}^{\circ}$ 357, 10/09/37, pág. 2); Guillem Muntaner i Pou (Treball, $\mathrm{n}^{\circ} 380,07 / 10 / 37$, pág. 7); Joan Manent i Garrido y Eugeni Gota i Rodés (Treball, $\mathrm{n}^{\circ} 403,03 / 11 / 37$, pág. 6); Josep Esteve (Treball, $\mathrm{n}^{\circ} 460,08 / 01 / 37$, pág. 6); y Joan LLoret i Gaset (Treball, $\mathrm{n}^{\circ} 462,1101 / 38$, pág. 10).
} 
principios de marzo de 1938 durante la estancia del secretario general del PSUC en la capital soviética. Durante su periplo por Moscú, Joan Comorera garantizó a las autoridades de la IC que su partido iniciaría la conversión en un partido comunista (continuando así la línea abierta en mayo de 1937 con el inicio de la erosión del PSUC como partido unificado), a cambio de que la IC garantizase la independencia del PSUC respecto al PCE. Así, con el visto bueno de Joan Comorera a la conversión de su organización en un partido comunista, se eliminaba el último escollo que dificultaba la transformación del PSUC en un partido comunista 33 .

No obstante, ¿cómo afectaría el inicio de la conversión del PSUC en un partido comunista a su militancia, teniendo presente que se trataba de una militancia heterogénea ideológica y socialmente? En principio, todo proceso de conversión en un partido comunista, también llamado bolchevización, afecta fundamentalmente a los aspectos ideológicos. Esta premisa se cumpliría en el caso del PSUC, pero con la gran particularidad y originalidad que la bolchevización de la militancia del partido catalán no se limitaría a los aspectos exclusivamente ideológicos, sino que también incidiría en su composición social. Así, el PSUC, desde el punto de vista de la militancia, centraría su bolchevización en los aspectos ideológicos, cosa lógica en la medida que éstos eran los aspectos en los que existía un mayor contraste entre la composición del PSUC y la de los partidos comunistas de Europa occidental agrupados bajo la IC; pero junto a ellos también se llevaría a cabo una bolchevización en la composición social, encaminada a aumentar el número de obreros en el PSUC. Esta voluntad de bolchevización en el ámbito social sería el resultado de una apuesta personal de la dirección del PSUC alineada con Joan Comorera, quienes veían así una forma suplementaria para dar muestras a la IC de la fidelidad del PSUC a este organismo internacional. El germen de esta opción ya se recogía abiertamente en el informe presentado por el secretario general del PSUC a la dirección de la IC el 20 de febrero de 1938, en el cual mostraba su descontento con la composición social del partido e, implícitamente, apostaba por incrementar la presencia obrera. Estas eran sus palabras:

Durante su crecimiento el partido se está liberando de las debilidades de todo partido joven. Su composición social es un $65 \%$ de obreros industriales, un $20 \%$ de campesinos y el resto funcionarios, gentes de profesiones liberales y pequeña burguesía. Esta composición social no nos satisface. Su formación ideológica es débil. El partido es joven y entre sus elementos absorbe a elementos procedentes de partidos republicanos y, en menor medida, de la Confederación Nacional del Trabajo, todos ellos con una pobre cultura marxista. El partido se esfuerza por corregir estas debilidades multiplicando las reuniones de activistas, perfeccionan-

33 Los detalles del informe presentado por Joan Comorera a la dirección de la IC, así como el trasfondo del inicio de la conversión del PSUC en un partido comunista, se encuentran analizados más detalladamente en mi trabajo de investigación de nueve créditos, bajo la reseña: PUIGSECH, Josep: El Partit Socialista Unificat de Catalunya..., op. cit., págs. 74-88. 
do su prensa, preparando la edición de una revista teórica, popularizando las enseñanzas de nuestros maestros y fortaleciendo nuestros cuadros ${ }^{34}$

No obstante, el análisis del perfil de los militantes del PSUC entre marzo 1938 y febrero 1939 está hipotecado por la escasa documentación primaria disponible, aunque ello no impide que realicemos un conjunto de reflexiones que ayudan a dibujar ese perfil.

En primer lugar debemos cuestionar las cifras oficiales aportadas desde el propio PSUC que cifraban en unos 90.000 el número de sus militantes. Sin lugar a dudas se trataba de una cifra desorbitada si tenemos presente la evolución que había seguido la militancia del PSUC durante la segunda mitad de 1937. En unos siete meses, desde julio 1937 hasta enero 1938, había incrementado en poco más de dos mil los militantes en la retaguardia, mientras que en el frente no llegaba ni a superar esa cifra. Así, pues, en siete meses, y teniendo una visión optimista; entre el frente y la retaguardia el PSUC habría adquirido un máximo de cinco mil militantes. Si aplicamos esta misma proporción a lo que restaba de 1938 y a los dos primeros meses de 1939, en estos trece últimos meses de la Guerra Civil el PSUC incrementaría su base militante en unos nueve mil doscientos efectivos. Esto supondría que al finalizar el conflicto bélico hablaríamos de unos 69.000 militantes, teniendo presente que se trata de una aproximación al alza. Pero, además, tampoco se debe olvidar que el crecimiento del número de militantes entre julio 1937 y enero 1938 había sido a la baja respecto al período julio 1936-junio 1937. Y si a ello le unimos que la evolución política, social, económica y cultural de la Cataluña republicana durante 1938 y los dos primeros meses de 1939 siguió unos parámetros similares a los del período comprendido entre julio 1937 y enero 1938, y que durante 1938 la negativa evolución del conflicto bélico para los intereses del bando republicano hizo crecer el pesimismo entre una población que cada vez deseaba más la finalización del citado conflicto, la cifra de los 69.000 militantes se nos antoja exagerada.

Este último aspecto nos permite reflexionar sobre un segundo elemento: los efectos directos que tuvo entre la militancia del PSUC el inicio del proceso de conversión en un partido comunista. Entre abril y junio 1938 se llevaron a cabo un conjunto de expulsiones de contenido esencialmente ideológico que, presentadas públicamente como actos de indisciplina, inmoralidad, cobardía, deserción o sabotaje, tenían como trasfondo el inicio de la conversión del PSUC en un partido comunista. Se expulsaba a militantes de base, pero también a algunos cuadros locales y comarcales, que no se acoplaban a esa conversión y que, además, no eran capaces de asumir los valores y los principios que requería todo buen militante comunista (disciplina, plena dedicación al partido...) 35. $^{35}$.

34 CRCEDHC. Fondo 495, circunscripción 74, caso $n^{\circ} 215$. COMORERA, Joan: Informe del camarada Comorera..., op. cit., págs. 15-16.

35. Los protagonistas de estas expulsiones se encuentran recogidos en los números de Treball correspondientes a abril, mayo y junio 1938.

Hispania, LXII/1, núm. 210 (2002) 259-282 
No obstante, a partir de julio 1938 estas expulsiones quedarían paralizadas. Eran los meses de la Batalla del Ebro y de la ofensiva final de las tropas sublevadas sobre Cataluña. La extrema gravedad de la situación militar llevaba al PSUC a concentrar sus objetivos y esfuerzos en la resistencia a la ofensiva de las fuerzas del general Franco. Ahora bien, la marcha atrás ya no era posible. Las expulsiones de abril-junio 1938 habían dejado huella y se convertían en un punto de referencia obligado. Aunque cuantitativamente no fueron excesivas, ya que afectaron a un total de treinta y cinco militantes, sí que fueron relevantes en términos cualitativos, porque indicaban que los militantes del PSUC tendrían que adecuarse a los parámetros de una militancia ideológicamente comunista. Parece lógico pensar que, a partir de marzo 1938, las nuevas incorporaciones se llevaron a cabo dedicando notable atención a la pureza ideológica de los nuevos militantes y, en menor medida, también prestando atención a su procedencia social si hacemos caso de las palabras de Joan Comorera que acabamos de reproducir. Así, pues, todo parece indicar que se cumplirían las promesas que había realizado el secretario general del PSUC a la dirección de la IC, durante la estancia del primero en Moscú, cuando aseguró que el PSUC tenía que modificar su composición social (la cual cosa pasaría inexorablemente por el incremento de la presencia obrera) y, especialmente, incrementar y potenciar, en el aspecto ideológico, la presencia comunista en base a la identificación con los principios del marxismo-leninismo-estalinismo.

Sin embargo, el inicio de la conversión del PSUC en un partido comunista sacó a la luz, nuevamente, las diferencias estructurales que existían entre este partido y el PCE. Mientras el partido catalán tenía que llevar a cabo cierta purificación de su militancia, el PCE no se veía obligado a ello, cuando la composición social de los dos partidos era relativamente similar. La llave de esta diferencia era la IC. A Moscú no le preocupaba que en el PCE hubiera militantes que no fuesen, mayoritariamente, obreros en el aspecto social ni/o, especialmente, comunistas en el aspecto ideológico, porque el PCE había nacido al calor de la IC, había vivido, durante sus más de quince años de existencia, siguiendo los dictados de Moscú y desde el ascenso de Iosif Stalin se había convertido en un partido comunista estalinista. En otras palabras, el PCE era una organización que ofrecía todo tipo de garantías y confianzas a Moscú. En cambio, el PSUC estaba lejos de merecer la confianza y las garantías que generaba el PCE entre las autoridades de la IC, ya que el PSUC ni aún era aún un partido comunista, ni tenía el beneficio de largos años de identificación y fidelidad a la IC. Por ello, si quería dar sensación de fidelidad y de garantías a los dirigentes de la IC, tenía que desprenderse de sus características como partido marxista de tipo nuevo, entre las cuales estaba en parte la diversidad social y, muy especialmente, la ideológica de sus militantes.

Un tercer aspecto que merece tenerse en consideración es la presencia de militantes del PCE dentro del PSUC. El avance de las tropas del general Franco sobre buena parte de la España republicana había traído consigo que un

Hispania, LXII/1, núm. 210 (2002) 259-282 
número significativo de militantes del PCE se refugiasen en Cataluña. Una vez que éstos estaban en tierras catalanas, buena parte pasaba a militar en el PSUC. Así lo reconoció el hombre fuerte que tenía la IC en España desde julio 1937, el italiano Palmiro Togliatti, quién constató que de los miembros del PCE refugiados en Cataluña, tan sólo aquellos que trabajaban en el aparato del Comité Central del PCE y en los ministerios creaban células directamente ligadas al PCE, mientras que el resto ingresaban en el PSUC ${ }^{36}$. La presencia de ese sector procedente del PCE jugó un papel de primer orden en el devenir del PSUC, ya que supuso la presencia de un colectivo que, en un buen número, ideológicamente era comunista, la cuál cosa tenía que facilitar la tarea de la purificación ideológica de la militancia del PSUC.

Finalmente, también debemos resaltar la incidencia negativa que ejerció en el crecimiento de la base militante del PSUC la desmoralización de la mayoría de los intelectuales catalanes durante 1938 y los dos primeros meses de 1939, cuando éstos habían jugado un papel importante en la tarea de hacer atractivo el PSUC entre la población catalana. A pesar de la desmoralización de este colectivo, tal y como lo demuestran sus diarios íntimos, entre marzo 1938 y enero 1939 el PSUC continuó intentando atraérselos, consciente del prestigio que tenían entre buena parte de la sociedad catalana. Para ello siguió utilizando como una de sus plataformas más importantes L'Esquella de la Torratxa, a la que se añadió una nueva publicación, el semanario Mirador, sustituto de las ya difuntas Papitu y Mirador.

Este era el estado de la cuestión de los militantes del PSUC en febrero 1939, cuando la totalidad del territorio catalán quedó bajo control de las fuerzas del general Franco. La llegada del exilio no haría más que confirmar y acentuar esta dinámica sobre la militancia del partido catalán.

Montmeló, 24 de abril del 2001

\section{SIGLAS UTILIZADAS:}

$\begin{array}{ll}\text { CADCI: } & \text { Centre de Dependents del Comerç i de la Indústria } \\ \text { CNT: } & \text { Confederación Nacional del Trabajo } \\ \text { ERC: } & \text { Esquerra Republicana de Catalunya } \\ \text { FAI: } & \text { Federación Anarquista Ibérica } \\ \text { FC del PSOE: } & \text { Federació Catalana del Partido Socialista Obrero Español } \\ \text { FNEC: } & \text { Federació Nacional d'Estudiants de Catalunya } \\ \text { FOUS: } & \text { Federación Obrera de Unidad Sindical } \\ \text { IC: } & \text { Internacional Comunista } \\ \text { JEREC: } & \text { Joventuts d'Esquerra Republicana-Estat Català } \\ \text { JSUC: } & \text { Joventuts Socialistes Unificades de Catalunya } \\ \text { PCC: } & \text { Partit Comunista de Catalunya }\end{array}$

36 Togliatti, Palmiro: Escritos sobre la guerra de España, Barcelona 1980, pág. 177. 
PCE:

PCF:

Partido Comunista de España

PCP:

Partido Comunista Francés

Partit Català Proletari

POUM: $\quad$ Partido Obrero de Unificación Marxista

PSOE: $\quad$ Partido Socialista Obrero Español

PSUC:

CRCEDHC: Centro Ruso de Conservación y Estudio de la Documentación de la Historia Contemporánea

UGT:

Unión General de Trabajadores

URSS:

Unión de Repúblicas Socialistas Soviéticas

USC:

Unió Socialista de Catalunya 